\title{
Prevalence of Malnutrition (Overweight and Underweight) in Children Aged 10-13 Years in Schools in Manipal and Utopia, Karnataka
}

\author{
Fatemeh Jahani ${ }^{1}$ \\ ${ }^{1}$ Department of Allied Hospitality Studies, Manipal Academy of Higher Education, Karnataka, India \\ Correspondence: Fatemeh Jahani, Department of Allied Hospitality Studies, Manipal Academy of Higher \\ Education, Karnataka, India
}

Received: May 7, 2020

Accepted: July 6, 2020

Online Published: November 30, 2020

doi:10.5539/jmbr.v10n1p94

URL: https://doi.org/10.5539/jmbr.v10n1p94

\begin{abstract}
Background. Malnutrition is a major health problem in India. It mostly affects children of school going age with serious health problems putting them at an increased risk for developing chronic diseases later in life. This study aims to study the prevalence of malnutrition (overweight and underweight) in children aged 10-13 years in schools in Manipal and Utopia, Karnataka.

Materials and Methods. In this study, a total 400 students were studied. Their anthropometric measurements like height, weight, BMI and MUAC, dietary pattern, physical activity level, and child eating behavior. Questionnaire was used to note the student's information. The data collected was subjected to statistical analysis using SPSS version 21, Diet Cal, and Anthroplus1.0.4.

Results. It was observed that in the childhood category 10-13 years there were $222(55.5 \%)$ male and $178(44.5 \%)$ female. According to the BMI for age $53.4 \%$ of them falls under the normal category; $22.3 \%$ falls under the mild wasting category; About $18.3 \%$ falls under the obese category and $8 \%$ falls under the moderate wasting category. There is no students falling under the severe wasting and overweight category according to the BAZ classification. When the height for age was done for all the children, about $36.3 \%$ falls under normal height; About 35.5\% falls under mild stunting; $19.3 \%$ falls under the moderate stunting; $8.3 \%$ falls under the severe stunting category; and $1 \%$ falls under tall category according to the HAZ classification.

Conclusions. In conclusion, mild stunting and wasting was observed among children. There are no students falling under the severe wasting and overweight category according to the BAZ classification.
\end{abstract}

Keywords: Malnutrition, Children, Overweight, Underweight, Karnataka, India

\section{Introduction}

Malnutrition is a major health problem in India. It mostly affects children of school going age with serious health problems putting them at an increased risk for developing chronic diseases later in life. As per WHO as today's children are the citizens of tomorrow's world their existence security and development is the essential for the coming growth of humanity (WHO, 1996). The calculated global frequency of overweight and obesity in children 5-19 years is 10\%. The occurrence arrays from 5.7\%in Pakistan to over 40\% in Mexico (Gupta, Goel, Shah, \& Misra, 2012).

The average value for the mutual prevalence of juvenile and adolescent overweight indicates that it was greater in north, compared to south India. The combined data after 2010 estimated a combined occurrence of 19.3 per cent of childhood overweight and obesity which was an important increase from the earlier occurrence of 16.3 per cent stated in 2001-2005 (Ranjani et al., 2016). The study included of 2938 school children in the age group of 10 - 16 years from eleven randomly selected English schools of Udupi District, Karnataka State. Out of 2938 children, 1666 (57\%) were males, 1216(42\%) were living in a family with four family members, 1773 (60\%) children were residing in the rural area, 1934(65.8\%) were in the age group of 13 - 16 years, 2193(74.6\%) were belonging to nuclear family, 1838 (63\%) were Hindus. Occurrence of childhood overweight/obesity the statistics show that 1904 (65\%) children were in the regular category of BMI, whereas 214 (7\%) were overweight and 141 (5\%) were obese (Nayak \& VinodBhat, 2011).

According to WHO (2014) overweight and obese children are likely to stay obese in adulthood and more likely 
to develop non communicable disease(Organization, 2014). Obesity and Underweight is becoming a major concern of children. Physical activity and proper diet intake is the only way to prevent overweight and obesity in childhood. Bowman et al. (2004) in his study indicates that Children with Undesirable nutrition also had higher BMI(Bowman \& Vinyard, 2004)

Overweight, Obesity and chronic diseases affect all society and culture; still no group has been affected however, more so than lower socioeconomic status individuals are more affected by this problem(Berge, Arikian, Doherty, \& Neumark-Sztainer, 2012). Chronic diseases are particularly preventable and can usually be categorized as lifestyle or behavioral diseases. Because chronic diseases are arguably lifestyle and behavioral disease.

There is a rise in the intake of bad quality foodstuffs together with the increase in sedentary activities and the decrease in physical activity (Ackard, Neumark-Sztainer, Story, \& Perry, 2003; Baranowski \& Domel, 1994; Cullen, Bartholomew, Parcel, \& Koehly, 1998; Fulkerson et al., 2006). Bad quality food mainly includes fast foods, sugar-sweetened beverages (soda or soft drinks), and high fat and high sugar snacks. Soft drink consumption has raised $100 \%$ between 1981 to 1995 therefore the prevalence of BMI has increased in turn increases the overweight, obesity and malnourishment among children (Ludwig, Peterson, \& Gortmaker, 2001).

Given the importance of the issue Malnutrition and the lack of a comprehensive study in recent years, the present study aimed to study the prevalence of malnutrition (overweight and overweight) in children aged 10-13 years in schools in Manipal and Utopia, Karnataka.

\section{Materials and Methods}

This is a descriptive cross - sectional study and carried out for seven months May 2017 to November 2017. Cross sectional studies are carried out at one time point or over a short period of time. This cross sectional study is conducted to identify the prevalence of malnutrition in children aged 10-13 Years in Schools in Manipal and Utopia, Karnataka. This study was conducted in schools located in Manipal and Udupi, Karnataka. The sample size was obtained using the result from previous study. Sample size was estimated to be 400 . Purposive sampling was used as sampling technique. Inclusion Criteria in this study Including all School going children of age 10-13 years both boys and girls and exclusion criteria including children with known case of thyroid hormone abnormalities and children with co-morbid condition which can lead to overweight or underweight.

The following tools and materials were used to carry out the study:

Questionnaire: Questionnaire was used to note the student's information. The component of the questionnaire was the general information about the students like age, gender, religion, family income and academic performance etc. and also the anthropometric measurement and some question related to child eating behaviour. A pre-validated semi structured questionnaire will be used for the data collection related to personal information, Physical activity, Dietary behaviour, and 24-hour diet recall for students and socio -Demographic information Child eating Behaviour.

Anthropometric measurement: Height was measured using measuring, weight is measured using weighing scale, BMI is expressed by formula, MUAC by MUAC tape, waist circumference is measured with help of measuring tape and waist to hip ratio is found. The body fat percentage was calculated using the formula The BMI classification are as follows (Table 1).

Table 1. Classification of BAZ and HAZ

\begin{tabular}{ll}
\hline BMI for age & Z Score \\
\hline Normal & +1 to -1 \\
Mild Wasting & -1 to -2 \\
Moderate Wasting & -2 to -3 \\
Obese & $>+2$ \\
Height for age & \\
Normal & +1 to 2 \\
Mild Stunting & -1 to -2 \\
Moderate Stunting & $>3$ \\
Severe Stunting & $<-3$ \\
Tall & $2-3$ \\
\hline
\end{tabular}

Child eating behavior pattern questionnaire: The eating behavior questionnaire is a multidimensional questionnaire measuring child eating behaviors i.e., Enjoyment of food, Desire to drink, Satiety Responsiveness, Slowness in eating, Emotional under eating and food fussiness. The total sore of each category was added and computed with different variable(Carnell \& Wardle, 2007). 
Dietary assessment: Was done using 24-hour dietary recall and food frequency questionnaire.

The physical activity questionnaire: Was used to determine the physical activity of the subjects. Standard measuring spoons and cups: Measuring cups and spoons were used to ask the quantity of food the subjects were consuming.

School record: Students general information and academic performance were taken from school record.

The data collected was subjected to statistical analysis using SPSS version 21, Diet Cal, and Anthroplus1.0.4.

\section{Results}

It was observed that in the childhood category $10-13$ years there were $222(55.5 \%)$ male and $178(44.5 \%)$ female. In the case of religion, it was observed that 360(90\%) were Hindu, 33(8.3\%) were Muslims, $6(1.5 \%)$ of students were Christian and $1(.3 \%)$ were found to be Buddhist. Also in this study observed that physical activity ranges from sedentary to very active in the age group of 10-13 years. $159(39.8 \%)$ was observed to be sedentary. About $168(42 \%)$ falls under low active group, $68(17 \%)$ is active whereas $5(1.3 \%)$ of them are very active.

Anthropometric measurement mainly Height, Weight, Waist Circumference, Hip Circumference, Waist Hip Ratio, BMI, MUAC, skinfold thickness of three sites Biceps, Abdomen and Subscapular of all students were taken part in the study. The mean values of all anthropometric measurement has been tabulated in Table 2 . The mean height and weight of the age group 10-13 years is 141.77 and 35.54 respectively. The mean value of waist circumference is 66.238 and hip circumference is 76.111 . So proportionately the mean of waist hip ratio is 1.262. 17.4304 is the mean value for BMI. The mean MUAC is 21.70. The mean value for Skinfold Biceps, Skinfold Abdomen and Skinfold subscapular is $15.623,16.175$ and 13.553 respectively.

Table 2. Mean Anthropometric indices of children (10-13 years)

\begin{tabular}{ll}
\hline Anthropometric Parameters & (Mean) \\
\hline Height & $141 \pm 9.07$ \\
Weight & $35.54 \pm 11.9$ \\
Waist Circumference & $66.23 \pm 9.1$ \\
Hip Circumference & $76.11 \pm 9.1$ \\
Waist Hip Ratio & $1.26 \pm 5.53$ \\
Body Mass Index(BMI) & $17.43 \pm 4.04$ \\
Mid Upper Arm Circumference(MUAC) & $21.70 \pm 8.28$ \\
Skinfold Biceps & $15.62 \pm 7.1$ \\
Skinfold Abdomen & $16.17 \pm 11.21$ \\
Skinfold Subscapular & $13.55 \pm 7.8$ \\
Body Fat Percentage & $17.3 \pm 6.1$ \\
\hline
\end{tabular}

Table 3 shows prevalence of stunting in study children based on HAZ classification. When the height for age was done for all the children, about 145(36.3\%) falls under normal height (+1 to-1 score) 141(35.5\%) falls under mild stunting ( -1 to $2 \mathrm{Z}$ score), $77(19.3 \%)$ falls under the moderate stunting (-2 to $-3 \mathrm{Z}$ score). $33(8.3 \%)$ falls under the severe stunting category ( $<-3 \mathrm{Z}$ score). $4(1 \%)$ falls under tall category $(+1 \mathrm{Z}$ score). Also according the results, the prevalence of wasting in study of children based on BAZ on age class According to the BMI for age classification $214(53.5 \%)$ of students falls under the normal category (+1 to $-1 \mathrm{Z}$ score) of weight. $89(22.3 \%)$ falls under the mild wasting category ( -1 to $2 \mathrm{Z}$ score). $73(18.3 \%)$ falls under the obese category ( -2 to $-3 \mathrm{Z}$ score). $24(6 \%)$ falls under the moderate wasting ( -2 to $-3 Z$ score).

Table 3. Prevalence of stunting in study children based on HAZ classification

\begin{tabular}{lll}
\hline Height for age classification & \multicolumn{2}{l}{ Late Childhood(10-13years) } \\
\cline { 2 - 3 } & $\begin{array}{l}\text { Frequency } \\
(\mathbf{n}=\mathbf{4 0 0})\end{array}$ & Percentage \\
\hline Normal(+1 to $\mathbf{Z}$ score) & 145 & 36.3 \\
Mild Stunting(-1 to-2 Z score) & 141 & 35.3 \\
Moderate Stunting(> 3Z score) & 77 & 19.3 \\
Severe Stunting(<-3 Z core) & 33 & 8.3 \\
Tall(2-3 score) & 4 & 1 \\
\hline
\end{tabular}

Dietary assessment of the students done by taking there dietary pattern and collecting 24 hours dietary recall from them and food frequency questionnaire by sending it to the parents. Dietary habits of the subject of the 
study show that out of 400 samples $350(80.1 \%)$ of students eats breakfast regularly and $1(0.2 \%)$ sleeps immediately after breakfast. $153(37.5 \%)$ of students have the mid-morning snacks while $29(0.5 \%)$ of students sleeps immediately after mid-morning snacks. The frequency of students having lunch is $398(97.5 \%)$ whereas 1(.2\%) sleeps immediately after lunch.372(91.2\%) have evening snacks while 6(1.5\%) sleeps immediately after evening snack. 391(95.8\%) used to have the dinner and 22(5.4\%) sleeps immediately after the dinner.82(20.1\%) have bed time snack and 33(8.1\%) sleeps immediately after the bed time snack.

Table 4. Food group adequacy classification of the subject of the study (10-13 yearrs)

\begin{tabular}{|c|c|c|c|}
\hline \multirow[t]{2}{*}{ Food group adequacy } & & \multicolumn{2}{|l|}{$\mathrm{N}=\mathbf{4 0 0}$} \\
\hline & & Frequency & Percent \\
\hline \multirow[t]{3}{*}{ cereals adequacy class } & Marginally inadequate & 387 & 96.8 \\
\hline & Marginally adequate & 11 & 2.8 \\
\hline & Adequate & 2 & 0.5 \\
\hline \multirow[t]{5}{*}{ Pulses adequacy class } & Substantially inadequate & 34 & 8.5 \\
\hline & Marginally inadequate & 90 & 22.5 \\
\hline & Marginally adequate & 97 & 24.3 \\
\hline & Adequate & 81 & 20.3 \\
\hline & Excess & 98 & 24.5 \\
\hline \multirow[t]{3}{*}{ GLV adequacy Class } & Substantially inadequate & 371 & 92.8 \\
\hline & Marginally inadequate & 28 & 7 \\
\hline & Marginally adequate & 1 & 3 \\
\hline \multirow[t]{3}{*}{ Roots and tubers adequacy class } & Substantially inadequate & 371 & 92.8 \\
\hline & Marginally inadequate & 28 & 7 \\
\hline & Marginally adequate & 1 & 0.3 \\
\hline \multirow[t]{4}{*}{ Other Vegetable adequacy class } & Substantially inadequate & 400 & 100 \\
\hline & Marginally inadequate & 0 & 0 \\
\hline & Marginally adequate & 0 & 0 \\
\hline & Adequate & 0 & 0 \\
\hline \multirow[t]{28}{*}{ Meat and poultry adequacy class } & Substantially inadequate & 240 & 60 \\
\hline & Marginally inadequate & 31 & 7.8 \\
\hline & Marginally adequate & 16 & 4 \\
\hline & Adequate & 28 & 7 \\
\hline & Excess & 85 & 21.3 \\
\hline & Substantially inadequate & 240 & 60 \\
\hline & Marginally inadequate & 31 & 7.8 \\
\hline & Marginally adequate & 16 & 4 \\
\hline & Adequate & 28 & 7 \\
\hline & Excess & 85 & 21.3 \\
\hline & Substantially inadequate & 83 & 20.8 \\
\hline & Marginally inadequate & 11 & 2.8 \\
\hline & Marginally adequate & 21 & 5.3 \\
\hline & Adequate & 12 & 3 \\
\hline & Excess & 273 & 68.3 \\
\hline & Substantially inadequate & 320 & 80 \\
\hline & Marginally inadequate & 69 & 17.3 \\
\hline & Marginally adequate & 11 & 2.8 \\
\hline & Substantially inadequate & 217 & 54.3 \\
\hline & Marginally inadequate & 37 & 19.3 \\
\hline & Marginally adequate & 37 & 9.3 \\
\hline & Adequate & 37 & 9.3 \\
\hline & Excess & 105 & 26.3 \\
\hline & Substantially inadequate & 88 & 22 \\
\hline & Marginally inadequate & 42 & 10.5 \\
\hline & Marginally adequate & 81 & 20.3 \\
\hline & Adequate & 85 & 21.3 \\
\hline & Excess & 104 & 26 \\
\hline
\end{tabular}

From the Table 4 it observed that energy intake is marginally inadequate for most of the subjects that is $108(25.4 \%)$, the intake is excess for $86(20.2 \%)$ of the students. $73(17.1 \%)$ intake is adequate, $86(20.2 \%)$ is marginally adequate while $47(11.5 \%)$ is substantially inadequate. Protein intake is marginally inadequate for the subjects that is $36(9 \%)$, the intake is excess for most of the $63 \%$ of the students. $37(9.3 \%)$ intake is adequate, $30(7.5 \%)$ is marginally adequate while $45(11.3 \%)$ is substantially inadequate. Carbohydrate intake is marginally inadequate for most of the subjects that is $129(30.3 \%)$, the intake is excess for $49(11.5 \%)$ of the students. 
$53(12.4 \%)$ intake is adequate, $129(30.3 \%)$ is marginally adequate while $101(23.7 \%)$ is substantially inadequate. PUFA intake is marginally inadequate for the subjects that is $57(13.4 \%)$, the intake is excess for most $212(49.8 \%)$ of the students. $34(8 \%)$ intake is adequate, $35(8.2 \%)$ is marginally adequate while $62(14.6 \%)$ is substantially inadequate. Monounsaturated fatty acid is marginally inadequate for the subjects that is $106(24.9 \%)$, the intake is excess for $97(22.8 \%)$ of the students. $59(13.8 \%)$ intake is adequate, $59(13.8 \%)$ is marginally adequate while most of the subject $106(24.9 \%)$ is substantially inadequate. Thiamine intake is marginally inadequate for most of the subjects that is $138(32.4 \%), 24(5.6 \%)$ intake is adequate, $52(12.2 \%)$ is marginally adequate while most of the subject $101(23.7 \%)$ is substantially inadequate. Riboflavin intake is marginally inadequate for $35(8.2 \%)$ of the subject, the intake is excess for $5(1.2 \%)$ of the students. $3(0.7 \%)$ intake is adequate, $35(8.2 \%)$ is marginally adequate while most of the subject $346(81.2 \%)$ is substantially inadequate. B3 intake is marginally inadequate for the subjects that is $105(24.6 \%)$, the intake is excess for $27(6.3 \%)$ of the students. 24(5.6\%) intake is adequate, $23(5.4 \%)$ is marginally adequate while most of the subject that is $221(51.9 \%)$ is substantially inadequate. B9 intake is marginally inadequate for most of the subjects that is $173(40.6 \%), 16(3.8 \%)$ intake is adequate, $97(22.8 \%)$ is marginally adequate while $104(24.4 \%)$ is substantially inadequate. Vitamin C intake is marginally inadequate for the subjects that is $59(13.8 \%)$, the intake is excess for $265(62.2 \%)$ of the students. 59(13.8\%) intake is adequate, $40(9.4 \%)$ is marginally adequate while $9(2.1 \%)$ is substantially inadequate. Retinol intake is marginally inadequate for the subjects that is $27(6.3 \%)$, the intake is excess for $3(0.7 \%)$ of the students. $2(0.5 \%)$ intake is adequate, $3(0.7 \%)$ is marginally adequate while most of the subject that is $365(85.7 \%)$ is substantially inadequate. Beta carotene intake is marginally inadequate for the subjects that is $78(18.5 \%)$, the intake is excess for $23(5.4 \%)$ of the students. $78(18.3 \%)$ intake is adequate, $79(18.5 \%)$ is marginally adequate while most of the subject $181(42.5 \%)$ is substantially inadequate. Calcium intake is marginally inadequate for the subjects that is $121(28.4 \%)$, the intake is excess for $11(2.6 \%)$ of the students. $12(2.8 \%)$ intake is adequate, $95(22.3 \%)$ is marginally adequate while most of the subject $161(37.8 \%)$ is substantially inadequate. Carbohydrate intake is marginally inadequate for the subjects that is $5(1.2 \%), 2(0.5 \%)$ is marginally adequate while most of the subject $393(92.3 \%)$ is substantially inadequate. Total dietary fibre intake is marginally inadequate for most of the subjects that is $100(23.5 \%)$, the intake is excess for $87(20.4 \%)$ of the students. $69(16.2 \%)$ intake is adequate, $72(16.9 \%)$ is marginally adequate while $72(16.9 \%)$ is substantially inadequate. B9 intake is marginally inadequate for the subjects that is $36(9 \%)$, the intake is excess for most of the subject163 (40.8\%). 127(31.8\%) intake is adequate, $70(17.5 \%)$ is marginally adequate while $4(1 \%)$ is substantially inadequate.

From the Table 4 it is observed that cereal intake is marginally inadequate for $387(96.8 \%)$ of the subject.11 $(2.8 \%)$ of the subject intake is marginally adequate. $2(0.5 \%)$ have adequate intake of cereals. Food group adequacy classification of the subject of the study (10-13 yearrs) presented in Table 4.

According to the Table 5, the mean intake of cereal is very less compared to RDA. The pulses and green leafy vegetable intake is almost meeting the RDA. Roots and tuber intake is inadequate compared to RDA. Other vegetables, Fruits and Milk intake is very high compared to the RDA. Nuts, Sugar, MFP intake is inadequate compared to RDA. Since most of the subject falls under the upper middle class the fruit and milk intake is seen to be very high (Table 5).

Table 5. The relation between mean food group intake and food group RDA

\begin{tabular}{lllllll}
\hline Food groups & Mean food group intake & Mean RDA intake & $\mathbf{9 5 \%}$ confidence interval & t-value & p-value \\
\hline Cereals & $178.58 \pm 31.74$ & $349.95 \pm 44.78$ & -176.75 & -165.97 & 62.471 & $\mathrm{P}<0.001^{* *}$ \\
Pulses & $62.56 \pm 68.32$ & $68.32 \pm 7.46$ & -8.02 & -3.48 & -4.990 & $\mathrm{P}<0.001^{* *}$ \\
Green Leafy Vegetables & $27.52 \pm 14.53$ & $27.52 \pm 14.53$ & .007 & .0007 & - & $\mathrm{P}<0.001^{* *}$ \\
Roots and Tubers & $34.34 \pm 14.1$ & $174.87 \pm 25.03$ & -143.35 & -137.69 & 97.714 & $\mathrm{P}<0.001^{* *}$ \\
Other Vegetables & $41.34 \pm 16.8$ & $20.04 \pm 8.91$ & 19.75 & 22.84 & 27.128 & $\mathrm{P}<0.001^{* *}$ \\
Fruits & $168.63 \pm 114.12$ & $41.34 \pm 16.87$ & 115.54 & 139.03 & 21.305 & $\mathrm{P}<0.001^{* *}$ \\
Milk & $338.91 \pm 98.00$ & $200 \pm 0.00$ & 129.28 & 148.55 & 28.350 & $\mathrm{P}<0.001^{* *}$ \\
Nuts and Oil & $9.18 \pm 14.91$ & $20.67 \pm 8.43$ & -13.05 & -9.92 & 14.414 & $\mathrm{P}<0.001^{* *}$ \\
Fats & $19.32 \pm 4.28$ & $168.63 \pm 114.12$ & -160.484 & -138.14 & 26.279 & $\mathrm{P}<0.001^{* *}$ \\
Sugar & $20.41 \pm 4.82$ & $100 \pm 0.00$ & -80.061 & -79.11 & 329.91 & $\mathrm{P}<0.001^{* *}$ \\
MFP & $108.42 \pm 116.86$ & $168.63 \pm 114.12$ & -73.17 & -47.253 & -9.134 & $\mathrm{P}<0.001^{* *}$ \\
\hline
\end{tabular}

Table 6 shows the comparison between the mean nutrient intakes with RDA. The macro nutrient considered are energy, protein, carbohydrate and total fat also micro nutrients like thiamine, riboflavin, B3, B6, B9, vitamin c, Retinol, Beta Carotene, Calcium and iron are added. From the paired t- test it is observed that all the micro and macro nutrients except poly saturated fatty acid have a significant difference compared to the RDA with the 
mean intake $\mathrm{p}$ value for all the micro nutrient is 0.00 which is $<0.001$ but the $p$ value for PUFA is 0.002 which is greater than 0.001 which states that there is no significant difference in the mean intake of mean intake compared to the RDA.

Table 6. Comparison of mean nutrient intake with RDA

\begin{tabular}{|c|c|c|c|c|c|c|}
\hline \multirow[t]{2}{*}{ Food groups } & \multirow[t]{2}{*}{ Mean Intake } & \multirow[t]{2}{*}{ Mean RDA intake } & \multicolumn{2}{|c|}{$95 \%$ confidence interval } & \multirow[t]{2}{*}{ t-value } & \multirow[t]{2}{*}{ p-value } \\
\hline & & & lower & Upper & & \\
\hline Energy & $1762.39 \pm 48.98$ & $2109.26 \pm 718.18$ & -424.54 & -269.18920 & -8.779 & $\mathrm{p}<0.001$ \\
\hline Protein & $53.49 \pm 20.82$ & $40.928 \pm 13.59$ & 10.03292 & 15.09587 & 9.757 & $\mathrm{p}<0.001$ \\
\hline Carbohydrate & $249.38 \pm 127.54$ & $350.73 \pm 116.70$ & -118.695 & -84.00506 & -11.48 & $\mathrm{p}<0.001 * *$ \\
\hline MUFA & $10725.35 \pm 6526.57$ & $13149.44 \pm 4397$ & -3234.21 & -1613.9707 & -5.883 & $\mathrm{p}<0.001$ \\
\hline PUFA & $9416.52 \pm 6204.33$ & $6574.72 \pm 2198.7$ & 2174.625 & 3508.98077 & 8.374 & $\mathrm{p}<0.001$ \\
\hline Total fat & $52.622 \pm 22.06$ & $65.75 \pm 21.03$ & -16.26 & 9.99 & 7.322 & $\mathrm{p}<0.001$ \\
\hline TSFA & $16688 \pm 2.56$ & $4602 \pm 15391.288$ & -10.02 & 7.373 & -3.763 & $\mathrm{p}<0.001$ \\
\hline Thiamine & $0.99 \pm 2.533$ & $1.4 \pm 0.00$ & -0.650 & -0.15267 & -3.171 & $\mathrm{p}<0.001$ \\
\hline Riboflavin & $0.80 \pm 2.741$ & $1.6 \pm 0.00$ & -1.06452 & -0.52555 & -5.800 & $\mathrm{p}<0.001$ \\
\hline VitaminB3 & $9.13 \pm 5.17$ & $15 \pm 0.00$ & -6.37448 & -5.35767 & -22.68 & $\mathrm{p}<0.001$ \\
\hline VitaminB6 & $1.11 \pm .425$ & $1 \pm 0.00$ & 0.07163 & 0.15520 & 5.336 & $\mathrm{p}<0.001$ \\
\hline VitaminB9 & $198.3717 \pm 55.27$ & $300 \pm 0.00$ & -107.062 & -96.19449 & -36.76 & $\mathrm{p}<0.001$ \\
\hline Vitamin C & $59.2343 \pm 24.18$ & $45 \pm 0.00$ & 11.85704 & 16.61164 & 11.771 & $\mathrm{p}<0.001$ \\
\hline Vitamin A & $200.3654 \pm 171.26$ & 600 & 235.35 & 212.88 & 12.11 & $\mathrm{p}<0.001$ \\
\hline Calcium & $500.9399 \pm 342.73$ & $800 \pm 0.00$ & -332.750 & -265.37011 & -17.45 & $* * \mathrm{p}<0.001$ \\
\hline Iron & $8.5535 \pm 3.20$ & $32 \pm 0.00$ & -23.7617 & -23.1314 & -146.2 & $\mathrm{p}<0.001$ \\
\hline TDF & $24.2454 \pm 8.62$ & $30.2157 \pm 10.05$ & -7.30157 & -4.63891 & -8.816 & $* * \mathrm{p}<0.001$ \\
\hline
\end{tabular}

** Significant at $1 \%$ level.

Table 7 indicates the child eating behaviours. From the table we can see that the mean of food responsiveness score is 10.63 and the mean of emotional overeating is 10.09 with total score 25 . The mean of the enjoyment of food is 10.4 that depicts that most of the student's falls under the high enjoyment of food. The mean of the desire to drink is 6.59 that means most of the students have a low desire to drink. Mean of satiety responsiveness is 11.45 that depicts most of the students have high satiety response. The mean of slowness in eating is 9.2 that depicts that most of the students are slow eaters. The mean of emotional under eating is 15.59 that depicts that most of the students fall under the high emotional under eating and the mean of food fussiness among students is 14.56 that means most of the students have food fussiness. Most of the subject have food avoidance more than food approach as the mean value of food avoidance is more than food approach.

Table 7. Eating Behaviour followed by child of age 10-13 years

\begin{tabular}{ll}
\hline Eating Behaviour & Mean \pm SD \\
\hline Food Approach & $9.03 \pm 1.48$ \\
Food Responsiveness & $10.63 \pm 3.04$ \\
Emotional Overeating & $10.09 \pm 0.94$ \\
Enjoyment of food & $10.4 \pm 2.38$ \\
Desire to drink & $6.59 \pm 2.11$ \\
Food Avoidance & $11.63 \pm 1.63$ \\
Satiety Responsiveness & $11.45 \pm 2.70$ \\
Slowness in eating & $10.2 \pm 2.27$ \\
Emotional Under eating & $8.59 \pm 3.64$ \\
Food Fussiness & $14.56 \pm 3.06$ \\
\hline
\end{tabular}

\section{Discussion}

Given the importance of the issue Malnutrition and the lack of a comprehensive study in recent years, the present study aimed to study the prevalence of malnutrition (overweight and overweight) in children aged 10-13 years in schools in Manipal and Utopia, Karnataka. It was observed that in the childhood category 10-13 years there were $222(55.5 \%)$ male and 178(44.5\%) female. According to the BMI for age 53.4\% of them falls under the normal category. $22.3 \%$ falls under the mild wasting category. $18.3 \%$ falls under the obese category and $8 \%$ falls under the moderate wasting category. There are no students falling under the severe wasting and overweight category according to the BAZ classification. When the height for age was done for all the children, about $36.3 \%$ falls under normal height. $35.5 \%$ falls under mild stunting, $19.3 \%$ falls under the moderate stunting.8.3\% falls under 
the severe stunting category. $1 \%$ falls under tall category according to the HAZ classification.

A cross sectional study carried out in the tea garden of Dibrugarh district of Assam assessed the dietary status of 605 adolescents based on their anthropometric measurements. Occurrence of stunting was $47.4 \%$ and $51.9 \%$ among boys and girls respectively in relation to NCHS reference, which reduced to almost $30 \%$ while Indian reference data was used. Incidence of thinness was higher among boys (59.5\%) than girls (41.3\%) counterparts(Medhi, Hazarika, \& Mahanta, 2007). A research done to examine the commonness of malnutrition using anthropometric methods in tribal students appearing a school in rural south India proved that $59.4 \%$ students were stunted(Thomas, Srinivasan, \& Sudarshan, 2013). A study found out that in rural Goa among adolescents (10-19 years) found out that $37.8 \%$ boys and $27.5 \%$ girls who joined the health camps were malnourished. According to the recommended daily allowance the energy intake of malnourished students was significantly lower (Banerjee, Dias, Shinkre, \& Patel, 2011). Data from two NHANES (National Health and Nutrition Examination Survey) surveys (1976-1980 and 2003-2004) show that the occurrence of individuals who are overweight and obese is growing: for the age group 10-19 years, the incidence improved from $6 \%$ to $16 \%$ around $10 \%$. There are several health problems at stake other than mere overweight/obesity. According to Swallen, Reither, Haas, and Meyer (2005), adolescents who have a higher than average BMI are more likely to have a poor physical quality of life(Swallen, Reither, Haas, \& Meier, 2005). The rise in Body Mass Index can in turn lead to more complicated health issues, mainly for young people. Thus, the phase at which one becomes overweight/obese can be serious. Being overweight as a child is considered a danger for being overweight as an adult which means that overweight children are more likely to face physical and emotional health issues as adults(Dietz, 1998; Reilly et al., 2005; Whitaker, Wright, Pepe, Seidel, \& Dietz, 1997). For children who are overweight, the somatic complications that can affect them has become a big issue. These adolescent are facing important mental complications. Obese adolescents are more likely to be harassed, oppressed, or discriminated against(Harper, 2006; McCrindle et al., 2007; Neumark-Sztainer et al., 2002). This can in turn lead to emotional distress, especially about looks(Viner et al., 2006). Li and colleagues (2007) found that girls who are obese, show a considerably higher depression rate than their ordinary weight counterparts, which can be explained by their disappointment(Li, Goran, Kaur, Nollen, \& Ahluwalia, 2007). The raised threat of disappointment is noteworthy with obese adolescents(Daniels et al., 2005). A raised risk of depression will generally result in a decrease in both confidence and efficacy(Berry, Naylor, \& Wharf-Higgins, 2005; Pinhas-Hamiel et al., 2006).

\section{Conclusions}

In conclusion, mild stunting and wasting was observed among children. There are no students falling under the severe wasting and overweight category according to the BAZ classification. According to the results of this study, about $36.3 \%$ falls under normal height; $35.5 \%$ falls under mild stunting; $19.3 \%$ falls under the moderate stunting; $8.3 \%$ falls under the severe stunting category; and $1 \%$ falls under tall category according to the HAZ classification.

\section{References}

Ackard, D. M., Neumark-Sztainer, D., Story, M., \& Perry, C. (2003). Overeating among adolescents: prevalence and associations with weight-related characteristics and psychological health. Pediatrics, 111(1), 67-74.

Banerjee, S., Dias, A., Shinkre, R., \& Patel, V. (2011). Under-nutrition among adolescents: A survey in five secondary schools in rural Goa. The National medical journal of India, 24(1), 8.

Baranowski, T., \& Domel, S. B. (1994). A cognitive model of children's reporting of food intake. The American journal of clinical nutrition, 59(1), 212S-217S.

Berge, J. M., Arikian, A., Doherty, W. J., \& Neumark-Sztainer, D. (2012). Healthful eating and physical activity in the home environment: results from multifamily focus groups. Journal of nutrition education and behavior, 44(2), 123-131.

Berry, T., Naylor, P., \& Wharf-Higgins, J. (2005). Stages of change in adolescents: an examination of self-efficacy, decisional balance, and reasons for relapse. Journal of Adolescent Health, 37(6), 452-459.

Bowman, S. A., \& Vinyard, B. T. (2004). Fast food consumption of US adults: impact on energy and nutrient intakes and overweight status. Journal of the american college of nutrition, 23(2), 163-168.

Carnell, S., \& Wardle, J. (2007). Measuring behavioural susceptibility to obesity: validation of the child eating behaviour questionnaire. Appetite, 48(1), 104-113.

Cullen, K. W., Bartholomew, L. K., Parcel, G. S., \& Koehly, L. (1998). Measuring stage of change for fruit and vegetable consumption in 9-to 12-year-old girls. Journal of behavioral medicine, 21(3), 241-254. 
Daniels, S. R., Arnett, D. K., Eckel, R. H., Gidding, S. S., Hayman, L. L., Kumanyika, S., . . Williams, C. L. (2005). Overweight in children and adolescents: pathophysiology, consequences, prevention, and treatment. Circulation, 111(15), 1999-2012.

Dietz, W. H. (1998). Health consequences of obesity in youth: childhood predictors of adult disease. Pediatrics, 101(Supplement 2), 518-525.

Fulkerson, J. A., Story, M., Mellin, A., Leffert, N., Neumark-Sztainer, D., \& French, S. A. (2006). Family dinner meal frequency and adolescent development: Relationships with developmental assets and high-risk behaviors. Journal of Adolescent Health, 39(3), 337-345.

Gupta, N., Goel, K., Shah, P., \& Misra, A. (2012). Childhood obesity in developing countries: epidemiology, determinants, and prevention. Endocrine reviews, 33(1), 48-70.

Harper, M. G. (2006). Childhood obesity: strategies for prevention. Family \& community health, 29(4), 288-298.

Li, C., Goran, M. I., Kaur, H., Nollen, N., \& Ahluwalia, J. S. (2007). Developmental trajectories of overweight during childhood: role of early life factors. Obesity, 15(3), 760-771.

Ludwig, D. S., Peterson, K. E., \& Gortmaker, S. L. (2001). Relation between consumption of sugar-sweetened drinks and childhood obesity: a prospective, observational analysis. The Lancet, 357(9255), 505-508.

McCrindle, B. W., Urbina, E. M., Dennison, B. A., Jacobson, M. S., Steinberger, J., Rocchini, A. P., . . Daniels, S. R. (2007). Drug therapy of high-risk lipid abnormalities in children and adolescents: a scientific statement from the American Heart Association Atherosclerosis, Hypertension, and Obesity in Youth Committee, Council of Cardiovascular Disease in the Young, with the Council on Cardiovascular Nursing. Circulation, 115(14), 1948-1967.

Medhi, G., Hazarika, N., \& Mahanta, J. (2007). Nutritional status of adolescents among tea garden workers. The Indian Journal of Pediatrics, 74(4), 343-347.

Nayak, B. S., \& VinodBhat, H. (2011). Prevalence of overweight/obesity among school children in Karnataka, South India. International Journal of Public Health Research, 35(1), 180-184.

Neumark-Sztainer, D., Falkner, N., Story, M., Perry, C., Hannan, P. J., \& Mulert, S. (2002). Weight-teasing among adolescents: correlations with weight status and disordered eating behaviors. International journal of obesity, 26(1), 123-131.

Organization, W. H. (2014). Report of the first meeting of the ad hoc working group on science and evidence for ending childhood obesity: 18-20 June 2014, Geneva, Switzerland.

Pinhas-Hamiel, O., Doron-Panush, N., Reichman, B., Nitzan-Kaluski, D., Shalitin, S., \& Geva-Lerner, L. (2006). Obese children and adolescents: a risk group for low vitamin B12 concentration. Archives of pediatrics \& adolescent medicine, 160(9), 933-936.

Ranjani, H., Mehreen, T., Pradeepa, R., Anjana, R. M., Garg, R., Anand, K., \& Mohan, V. (2016). Epidemiology of childhood overweight $\&$ obesity in India: A systematic review. The Indian journal of medical research, 143(2), 160 .

Reilly, J. J., Armstrong, J., Dorosty, A. R., Emmett, P. M., Ness, A., Rogers, I., . . Sherriff, A. (2005). Early life risk factors for obesity in childhood: cohort study. Bmj, 330(7504), 1357.

Swallen, K. C., Reither, E. N., Haas, S. A., \& Meier, A. M. (2005). Overweight, obesity, and health-related quality of life among adolescents: the National Longitudinal Study of Adolescent Health. Pediatrics, 115(2), 340-347.

Thomas, R., Srinivasan, R., \& Sudarshan, H. (2013). Nutritional status of tribal children and adolescents in rural south India: The effect of an NGO delivered nutritional programme. The Indian Journal of Pediatrics, $80(10), 821-825$.

Viner, R., Haines, M., Taylor, S., Head, J., Booy, R., \& Stansfeld, S. (2006). Body mass, weight control behaviours, weight perception and emotional well being in a multiethnic sample of early adolescents. International journal of obesity, 30(10), 1514-1521.

Whitaker, R. C., Wright, J. A., Pepe, M. S., Seidel, K. D., \& Dietz, W. H. (1997). Predicting obesity in young adulthood from childhood and parental obesity. New England journal of medicine, 337(13), 869-873.

WHO. (1996). Physical status: The use of and interpretation of anthropometry, Report of a WHO Expert Committee. 


\section{Copyrights}

Copyright for this article is retained by the author(s), with first publication rights granted to the journal.

This is an open-access article distributed under the terms and conditions of the Creative Commons Attribution license (http://creativecommons.org/licenses/by/4.0/). 